\title{
Application of the surface potential data to elucidate interfacial equilibrium at ceria/aqueous electrolyte interface
}

\author{
Danijel Namjesnik ${ }^{1}$, Sanela Mutka ${ }^{2}$, Damir Iveković ${ }^{3}$,Andreja Gajović ${ }^{4}$, Marc \\ Willinger $^{5}$, Tajana Preočanin ${ }^{1 *}$
}

${ }^{I}$ Division of Physical Chemistry, Department of Chemistry, Faculty of Science, University of Zagreb, Horvatovac 102a, HR-10000 Zagreb, Croatia

${ }^{2}$ Pliva Croatia Ltd., Research and Development, Prilaz baruna Filipovića 25, HR-10000 Zagreb, Croatia

${ }^{3}$ Division of Chemistry and Biochemistry, Faculty of Food Technology and Biotechnology, University of Zagreb, Pierottijeva 6, HR-10000 Zagreb, Croatia

${ }^{4}$ Division of Materials Physics, Ruđer Bošković Institute, Zagreb, Bijenička c. 54, HR-10000 Zagreb, Croatia

${ }^{5}$ Fritz-Haber-Institute der Max-Planck-Gesellschaft, Faradayweg 4-6, D-14195 Berlin, Germany

Corresponding author:

Tajana Preočanin; tajana@,chem.pmf.hr; tel: +385 14606 154; fax: +385 14606131

Acknowledgments: This work has been supported by Croatian Science Foundation under the project (IP-2014-09-6972) and by Croatian Academy of Sciences and Arts" under the project "Surface properties of cerium oxide nanoparticles in aqueous electrolyte solutions". The authors are grateful to the Laboratory for Precipitation Processes, Ruđer Bošković Institute (Zagreb, Croatia) for BET measurements, and dr. Dominik Cinčić (the Department of Chemistry, the Faculty of Science, the University of Zagreb) for powder X-ray diffraction measurements. 


\begin{abstract}
Interfacial properties of ceria $\left(\mathrm{CeO}_{2}\right)$ nanoparticles and highly organized ceria crystal planes $\{111\}$ and $\{100\}$ in the aqueous electrolyte solution were studied.It was confirmedby high resolution electron spectroscopy that a primary ceria nanoparticle consistsmostly of two crystal planes $\{111\}$ and $\{100\}$ with different surface sites exposed to the aqueous electrolyte solution. Interfacial properties of ceria nanoparticles are directly related to the reactivity and surface densities of existing surface sites. However, surface characterization(potentiometric titrations and electrophoretic measurements) provides only some kind of average surface properties i.e. average surface charge densities and surface potentials. The point of zero charge of ceria nanoparticles was measured to be between $\mathrm{pH}_{\mathrm{pzc}}=7.5$ and 9.0, and the isoelectric point at $\mathrm{pH}_{\mathrm{iep}}=6.5$. With the purpose of understanding ceria nanoparticles surface charging the inner surface potentials ofceria macro crystal planes $\{111\}$ and $\{100\}$ were measured, by means of single crystal electrodes, as a function of $\mathrm{pH}$ and ionic strength. The inner surface potential directly affects the state of ionic species bound to a certain surface plane and is thus an essential parameter governing interfacial equilibrium. From the measured $\Psi_{0}(\mathrm{pH})$ data and applying the MultiSite Complexation Model the thermodynamic equilibrium constants of doubly-coordinated $\equiv \mathrm{Ce}_{2}-\mathrm{OH}$ (at the $\{100\}$ ceria crystal plane) as well assinglycoordinated $\equiv \mathrm{Ce}_{1}-\mathrm{OH}$ and triply-coordinated $\equiv \mathrm{Ce}_{3}-\mathrm{OH}$ (at the $\{111\}$ ceria crystal plane) were evaluated. The $\Psi_{0}(\mathrm{pH})$ function differs for two examined ceria planes, however the inner surface potentials of both planes depend on ionic strength having a broad electroneutrality region between $\mathrm{pH}=6$ and $\mathrm{pH}=9$.
\end{abstract}

\title{
Keywords
}

Ceria, nanoparticles, single crystal, surface properties, inner surface potential, surface complexation, MUSIC model 


\section{Introduction}

Ceria, cerium(IV) oxide, plays an important role in industrial processes, the biomedical applications (Karakoti et al. 2008), the production of renewable energy (Melchionna and Fornasiero 2014, Reed et al. 2014) and catalysis(Si and Flytzani-Stephanopoulos 2008). Additionally, the toxicity of ceria nanoparticles has been reported(Ould-Moussa et al. 2014). Depending upon the synthesis condition, ceria could be obtained as nanocrystals, colloidal aggregates, or even macro crystals (Reed et al. 2014). The reactivity of ceria nanoparticles is influenced by their size (Reed et al. 2014), while the behavior of the aqueous ceria suspension depends on the ceria surface structure and the structure of the electrical interfacial layer (Nabavi et al. 1993, Gulicovski et al. 2014).

In the contact of solid metal oxide surfaces with the aqueous electrolyte solutions several processes occur. Metal atoms at the surface $(\equiv \mathrm{M})$ react with water molecules (hydrolysis) forming amphoteric surface sites $\left(\equiv \mathrm{MOH}^{z}\right)$ which can be protonated $\left(\equiv \mathrm{MOH}_{2}{ }^{z+1}\right)$ or deprotonated $\left(\equiv \mathrm{MO}^{z-1}\right)$ (Schindler and Stumm 1987, Lützenkirchen 2006). The distribution and accumulation of ions (hydroxide ions, hydronium ions, cations and anions) result in the formation of an electrical interfacial layer. Theelectrical charge at the solid liquid interface determines the behavior of the system, such as colloid stability, adhesion, adsorption and electrokinetic phenomena (Lyklema 1995).

In order to analyze the processes within the interfacial layer a certain model with several layers at the interface divided by characteristic planes should be assumed. For that purpose, in this article, the General Model of EIL (GM-EIL) of a metal oxide in aqueous electrolyte solution (Kallay et al. 2006) has been used. According to GM-EIL, within the solid phase, the electrical potential is assumed to be constant and equal to the inner surface potential $\Psi_{0}$ corresponding to the 0 -plane that divides the solid from the liquid phase. The surface charge density of this plane, $\sigma_{0}$, is determined by the interaction of potential determining ions with active surface sites $\left(\mathrm{H}^{+}\right.$and $\mathrm{OH}^{-}$ions). The charge at the 0-plane is partially compensated by the association of charged surface groups with counterions of opposite signs. These associated counterions are located at the $\beta$-plane characterized by the potential $\Psi_{\beta}$. The onset of the diffuse layer which extends to the bulk of the solution is at the d-plane with the potential $\Psi_{\mathrm{d}}$. Within the diffuse layer the electrokinetic slip plane (e-plane) is located dividing the mobile from the stagnant liquid at the interface and is characterized by 
the electrokinetic $\zeta$-potential (Hunter 1981, Delgado 2007). In the absence of specific adsorption, and in the symmetric case (same affinities of anions and cations for association with oppositely charged groups) and at low ionic strength, the point of zero potential $\mathrm{pH}_{\mathrm{pzp}}$ $\left(\Psi_{0}=0\right)$ coincides with the electroneutrality point $\mathrm{pH}_{\mathrm{eln}}$ determined by thermodynamic interfacial equilibrium constants, the electrokinetic isoelectric point $\mathrm{pH}_{\mathrm{iep}}(\zeta=0)$ and with the point of zero charge $\mathrm{pH}_{\mathrm{pzc}}\left(\sigma_{0}=0\right)$, as obtained by mass titration or potentiometric acid-base titrations of the suspensions (Kallay et al. 2010).

According to the Surface Complexation Model (Lützenkirchen 2006) several reactions may take place at the interface. Charging reactions could be represented by the binding of potential determining ions to active surface sites. The surface concentration densities and types of the specific surface sites are determined by the surface structure. A crystalline colloidalor nanoparticle exposes different crystal planes to the solution, different planes are characterized by different values of thermodynamic equilibrium parameters, as predicted by the MUltiSIte Complexation(MUSIC) model (van Riemsdijk et al. 1986, Hiemstra et al. 1989, Hiemstra and van Riemsdijk 2006). Consequently, the overall interfacial characteristics, as well as evaluated equilibrium parameters (e.g. equilibrium constants), of colloidal and nanoparticles are averaged, depending on the features of individual planes and on their abundance. Additionally, the individual crystal planes at colloidal and nanoparticles are connected through the bulk of the crystal which may result in mutual interactions of connected planes (Kallay et al. 2014).In this work the ceria surface has been chosen due tothe relativelysimple preparation of ceria nanoparticles(Antonova et al. 2001, $\mathrm{Xu}$ et al. 2008, Morris et al. 2013) as well as to the availability of the macro single crystal with a defined crystal plane.

The aim of this article is to determine the properties of ceria nanoparticles (size, shape, structure, colloid stability, surface charge density as well as the electrokinetic potential) and the surface properties of individual ceria surface planes $\{111\}$ and $\{100\}$ (the inner surface potential). Results were interpreted by the MUSIC model (van Riemsdijk et al. 1986, Hiemstra et al. 1989, Hiemstra and van Riemsdijk 2006) andthe thermodynamic equilibrium constants of surface sites protonation were evaluated. The measured surface properties of flat well-defined ceria crystal planes and evaluated thermodynamic parameters were analyzed and correlated with the measured surface properties of ceria nanoparticles. 


\section{Materials and methods}

\subsection{Preparation of ceria nanoparticles}

Cerium (IV) oxide nanoparticles used in this study were prepared by hydrolysis of $\mathrm{Ce}\left(\mathrm{NO}_{3}\right)_{3}\left(\mathrm{Ce}\left(\mathrm{NO}_{3}\right)_{3} \times 6 \mathrm{H}_{2} \mathrm{O}\right.$ Sigma Aldrich) at room temperatureaccording to the procedure described in literature ( $\mathrm{Xu}$ et al. 2008). Sodium hydroxide solution $\left(125 \mathrm{~mL}, c=1 \mathrm{~mol} \mathrm{dm}^{-3}\right)$ was added to the cerium(III) nitrate aqueous solution ( $\left.5 \mathrm{~L}, \gamma=2.5 \mathrm{~g} \mathrm{dm}^{-3}\right)$ under constant stirring. Immediately after mixing, the reaction took place and formation of a purple precipitate was observed. Suspensions was stirred continuously for twenty hours at room temperature, the precipitate turned yellow andpH of suspension was measured to be around 11. The precipitate was purified by intensive washingwith deionized water until the conductivity of the supernatant reached the conductivity of deionized water. After purification, the precipitate was evaporated under reduced pressure. Dry ceria powder was stored in a glass bottle at room temperature.

\subsection{Structural and morphological characterization of ceria nanoparticles}

The X-ray powder diffraction was carried out with the Bruker X-ray powder diffractometer (Billerica, MA, USA) employing the $\mathrm{Cu} \mathrm{K \alpha}$ radiation $(\lambda=1.54185 \AA)$, operated at $40 \mathrm{kV}$ and $30 \mathrm{~mA}$.

The high-resolution transmission electron microscopy (HR-TEM) of ceria samples was performed using Philips CM200 FEG transmission electron microscope operated at 200 $\mathrm{kV}$. For the TEM measurements, the samples were first suspended in chloroform by sonication, then a small drop of the suspension was transferred onto the carbon-coated copper grid and dried.

The specific surface area of prepared cerium(IV) oxide nanoparticles of $169 \mathrm{~m}^{2} \mathrm{~g}^{-1}$ was determined by the multiple Brunauer, Emmett and Teller (BET) method (Micromeritics, Gemini) using liquid nitrogen.

The hydrodynamicdiameter of ceria nanoparticles was measured,immediately after preparation and again after sonification,by the Dynamic Light Scattering (DLS) method using a 90Plus Brookhaven instrument. 


\subsection{Surface characterization of Ceria nanoparticles}

Potentiometric mass titration was used to determinethe effects of ionic strength on the surface charge densityand on the point of zero charge. The mass titration method was initially developed for metal (hydr)oxides and was limited to pure samples(Noh and Schwartz 1989), but lately was extended for contaminated samples (Žalac and Kallay 1992). The method is based on the fact that $\mathrm{pH}$ approaches the limiting value $\left(\mathrm{pH}_{\infty}\right)$ by addition of solid powder to an aqueous medium. The limiting $\mathrm{pH}_{\infty}$ value, at a high solid content is equal to $\mathrm{pH}_{\mathrm{pzc}}$. The advantage of the potentiometric mass titration method is that one does not need to perform blank titration, which is the case in the potentiometric acid-base titration of colloid and nanoparticles suspension. The mass titration method was developed (Preočanin and Kallay 1998, Preočanin and Kallay 2006) for the determination of surface charge density in the 0plane $\left(\sigma_{0}\right)$ using the following equation:

$$
\sigma_{0}=-\frac{F}{s y \gamma}\left(10^{-\mathrm{pH}}-10^{-\mathrm{pH}_{\mathrm{in}}}-10^{\mathrm{pH}-\mathrm{p} K_{\mathrm{w}}}+10^{\mathrm{pH} \text { in }-\mathrm{p} K_{\mathrm{w}}}\right)
$$

where $\gamma$ is a mass concentration of metal oxide, $\mathrm{pH}$ is measured in the bulk of the suspension, $\mathrm{pH}_{\text {in }}$ is initial $\mathrm{pH}$ of the aqueous electrolyte solution (without solid particles), $F$ is a Faraday constant, $s$ is a specific surface area, $y$ is an activity coefficient and $K_{\mathrm{w}}$ a thermodynamic equilibrium constant of $\mathrm{H}^{+}$and $\mathrm{OH}^{-}$neutralization in the bulk of the solution.

Weighed amounts of cerium(IV) oxide nanoparticles were added subsequently to aqueous electrolyte solutions. Ionic strength was controlled by sodium chloride $10^{-3} \mathrm{~mol} \mathrm{dm}^{-3}$ and $10^{-2} \mathrm{~mol} \mathrm{dm}^{-3}$, and initial $\mathrm{pH}_{\text {in }}$ was adjusted by $\mathrm{HCl}$ or $\mathrm{NaOH}$. For each ionic strength, mass titrations were performed from the initial acidic $\left(\mathrm{pH}_{\mathrm{in}} \approx 3\right)$, neutral $\left(\mathrm{pH}_{\text {in }} \approx 6.2\right)$ and basic $\left(\mathrm{pH}_{\mathrm{in}} \approx 11\right)$. The maximum ceria mass concentration was $80 \mathrm{~g} \mathrm{dm}^{-3}$, the more concentrated dispersions were too dense for homogenous stirring and a reproducible $\mathrm{pH}$ measuring. After each addition the suspension was treated with ultrasound for one minute and stirred for three minutes.After equilibration the $\mathrm{pH}$ value was measured by a glass electrode (Metrohm 6.0123.100) connected to a Metrohm 713 pH-meter. All measurements were performed at $25^{\circ} \mathrm{C}$ and under argon atmosphere to avoid a dissolution of carbon dioxide.

The electrophoretic mobilities of cerium(IV) oxide nanoparticles were measured using a 90Plus Brookhaven Zeta potential analyzer. The electrokinetic measurementsof 0.1 $\mathrm{mg} \mathrm{ml}^{-1}$ ceria nanoparticles dispersed in $10^{-2} \mathrm{~mol} \mathrm{dm}^{-3}$ and $10^{-3} \mathrm{~mol} \mathrm{dm}^{-3}$ hydrochloric acid solution wereperformed. Ionic strength was controlled by the addition of sodium chloride. 
Solutions were titrated with $10^{-1} \mathrm{~mol} \mathrm{dm}{ }^{-3}$ sodium hydroxide solution, covering a range from a $\mathrm{pH} \approx 3$ to $\mathrm{pH} \approx 11$. Measurements were performed at room temperature. Electrophoretic mobilities were converted to $\zeta$-potential using the Smoluchowski equation (Hunter 1981).

\subsection{Inner surface potential at the ceria/aqueous electrolyte interface}

Two ceria single crystals exposing $\{111\}$ and $\{100\}$ faces were purchased from SurfaceNet GmbH. The crystals dimensions were $4 \times 4 \times 0.5 \mathrm{~mm}$, one side polished.Ceria single crystal electrodes ( $\mathrm{SCrE}$ ) were constructedin the way that the ceria crystal plane, $\{111\}$ and $\{100\}$ respectively, was exposed to the aqueous electrolyte solution, as shown on Figure 1.The nonporous ceria single crystal electrode consisted of a Plexiglas body with a single crystal mounted at its end and sealed with epoxy resign. Internal electric contact was ensured by mercury into which a graphite electrode rod was immersed. A copper wire was connected to the graphite rod. The details are given elsewhere (Kallay et al. 2005; Preočanin and Kallay 2008; Zarzycki et al. 2010; Preočanin and Kallay 2013). The electric resistance (impedance) of ceria single crystal was measured directly and found to be $\mathrm{xx} M \Omega$, so that the impedance of the $\mathrm{pH}$-meter was sufficiently high $\left(Z \sim 10^{12} \Omega\right)$ to ensure reversible condition, i.e. the absence of a potential drop due to the passage of current through electrode. Accordingly, the measured electrode potential $\left(E_{\mathrm{SCr}}\right)$ was result of the ionic adsorption equilibrium within the ceria/aqueous electrolyte solution electrical interfacial layer only.

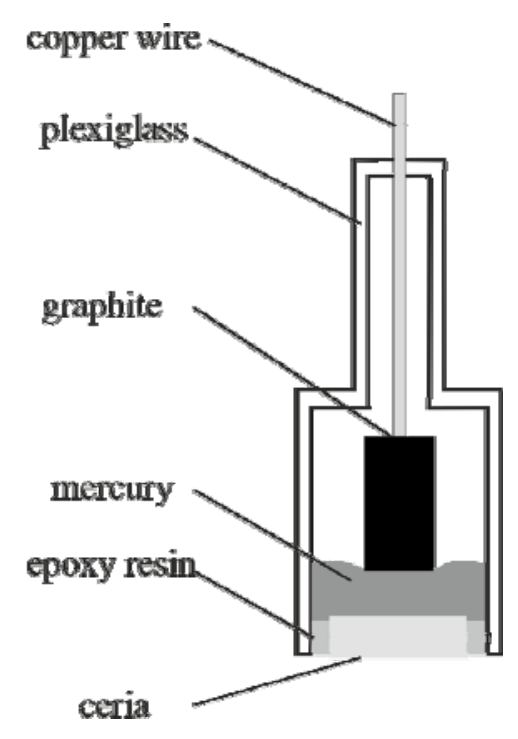

Figure 1Ceria single crystal electrode 
The potentials of each electrode were measured simultaneously asthe function of $\mathrm{pH}$. $\mathrm{pH}$ was measured by a combined $\mathrm{pH}$ electrode (Metrohm 6.0234 .100 with $\mathrm{Ag}|\mathrm{AgCl}| \mathrm{KCl} ; 3$ mol $\mathrm{dm}^{-3}$ ) a reference electrode, which was used as reference electrode for all three measuring electrodes).Thesolutions of $\mathrm{KOH}$ (Sigma-Aldrich Laborchemikalien $\mathrm{GmbH} ; c=$ $0.1 \mathrm{~mol} \mathrm{dm}^{-3}$, diluted to $c=0.01 \mathrm{~mol} \mathrm{dm}^{-3}$ ) and $\mathrm{HCl}$ (VWR International S.A.S. $c=0.01 \mathrm{~mol}$ $\mathrm{dm}^{-3}$ ) were used for the acid base titrations.

Each single crystal electrode was connected to a separate Metrohm $713 \mathrm{pH}$ meter, while the $\mathrm{pH}$ electrode was connected to the Metrohm $827 \mathrm{pH}$ meter. The solution was thermostated at $25^{\circ} \mathrm{C}$, and instead of measuring $\mathrm{pH}$, the $\mathrm{pH}$ meters were set to measure electrode potentials in $2 \mathrm{~s}$ periods. The titration was performed by Metrohm 665 dosimats, controlled and programmed by a computer. The data from $\mathrm{pH}$ meters werecontinuously collected by the computer.

The experimentswere designed as follows:The initial solution of $\mathrm{HCl}$ (deionized boiled water, degassed with argon, $\mathrm{pH}=3$ ) was titrated with $\mathrm{KOH}$ until $\mathrm{pH}=11$ was reached. The titration was repeated three times under the same conditions. The measurements of $\mathrm{SCr}$ electrode potential were taken with stirring off, after each addition of $\mathrm{KOH}$ followed by $15 \mathrm{~min}$ of stabilization period.The measured single crystal electrode potentials were plotted as $E_{\mathrm{SCr}}(\mathrm{pH}) v s . \mathrm{pH}$ and the point of zero potential was determined from the inflexion point of the curve (Preočanin and Kallay 2013).

Surface equilibrium parameters were calculated by comparing numerical simulations to experimental datausing the MUSIC model.

\section{Results and discussion}

\subsection{Morphological and structural properties of the prepared ceria nanoparticles}

The X-ray diffractogram of the prepared ceria sample is shown in Figure 2. All observed diffraction maxima can be indexed to the cubic fluorite $\mathrm{CeO}_{2}$ structure (JCPDS 810792), confirming that the prepared sample was pure cerium(IV) oxide. The diffraction peaks are broad due to a small particle size, which was estimated to be $\mathrm{XX} \mathrm{nm}$ by the Scherrer equation (Langford and Wilson 1978, Monshi et al. 2012). 


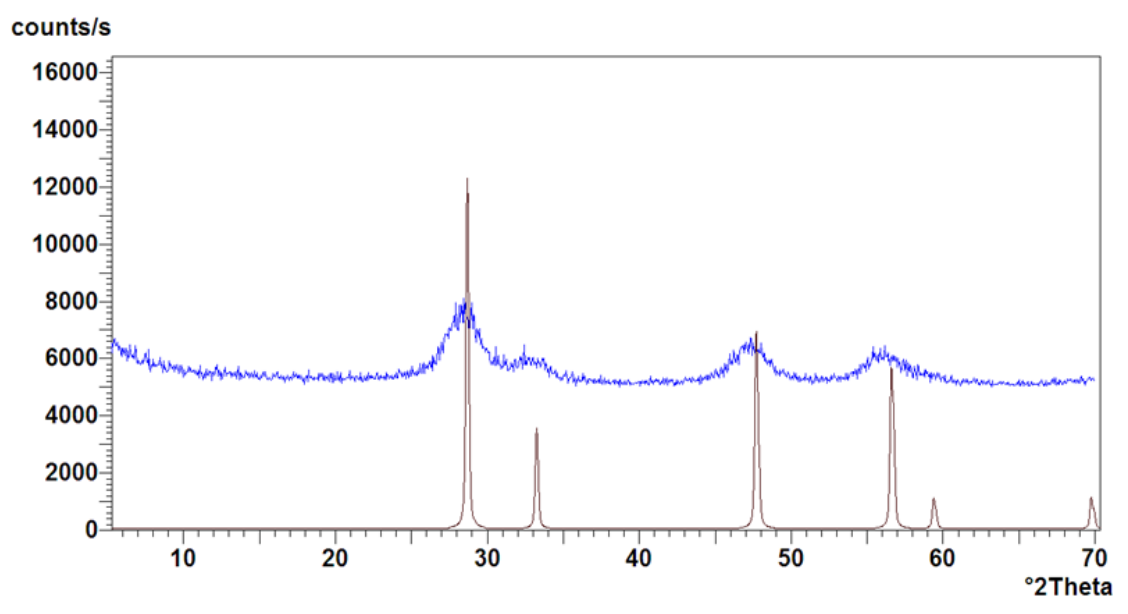

Figure 2The XRD pattern of the prepared ceria sample

TEM images of the samples (Figure 3) revealed that the ceria nanoparticles were of a fairly uniform size distribution between 3.5 and $5 \mathrm{~nm}$. High-resolution TEM of ceria nanoparticles showed that individual nanoparticles are single-crystaline and preferentially oriented along [110], with a dominant lattice fringes corresponding to the $\{111\}$ and $\{002\}$ lattice planes (Figure 2.b). Therefore, it follows that the preferred shape of prepared ceria nanoparticles is truncated octahedron bounded with the $\{111\}$ and $\{100\}$ planes. The $\{111\}$ lattice fringes were observed to spread over the area occupied by several ceria nanoparticles (Figure 2.c), indicating that the nanoparticles form aggregates in which the individual nanocrystals were stacked by sharing the faces of the same type (viz. $\{111\}$ to $\{111\}$, or $\{100\}$ to $\{100\})$. The bulk structure of ceria is made of Ce(IV), each coordinated to eight oxygen atoms, while each oxygen is coordinated to four cerium atoms (Reed et al. 2014). The surface of a single nanoparticle is made of different crystallographic planes. 


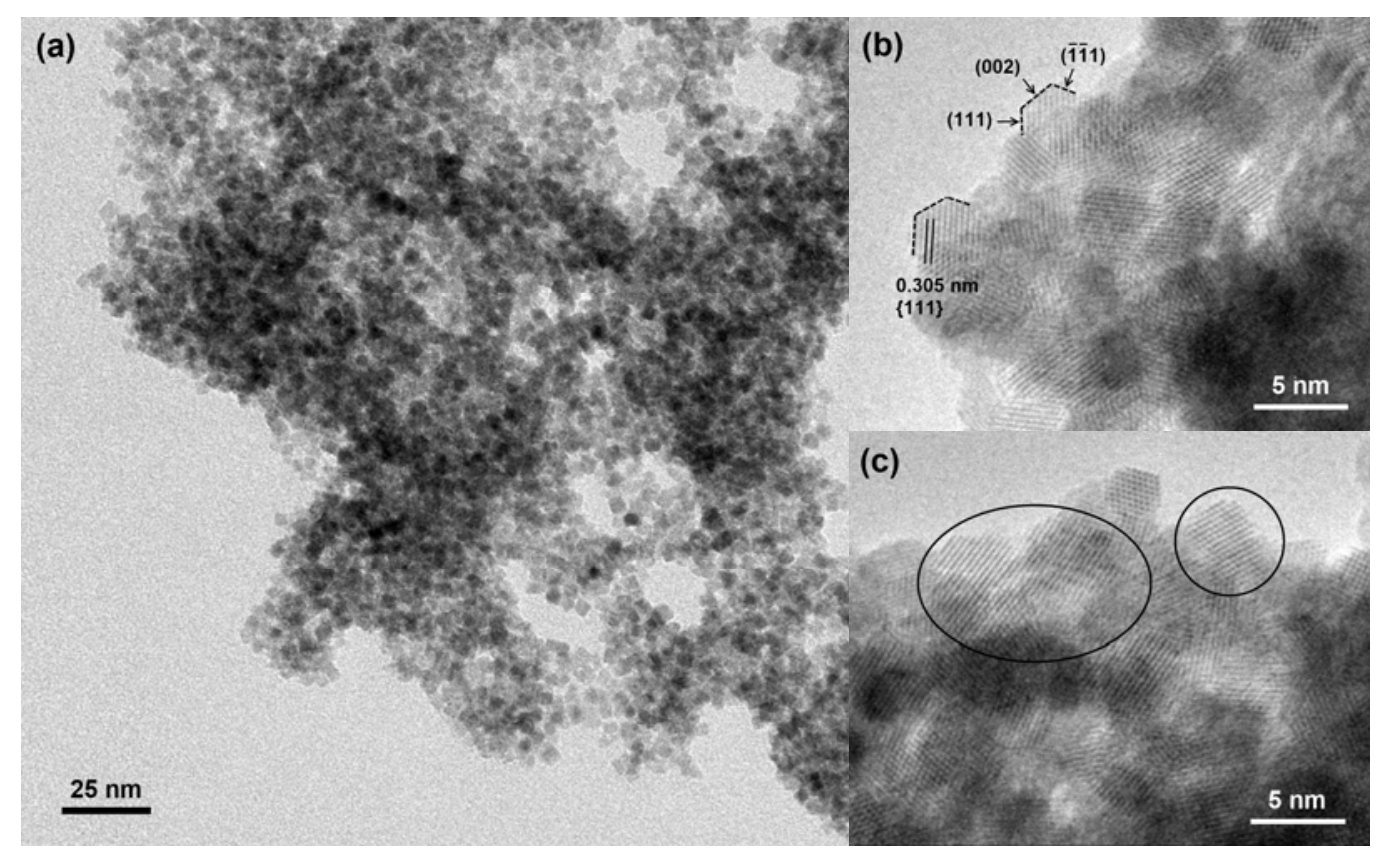

Figure 3 TEM micrographs of the prepared ceria nanoparticles. Lattice planes that correspond to the facets of the ceria nanocrystals are indicated by arrows in the high-resolution TEM image (fig. b). Encircled area in fig. $c$ indicates the $\{111\}$ lattice fringes in a nanoparticle agglomerate.

The hydrodynamic diameter of ceria particles, immediately after preparation, in the basic solution $(\mathrm{pH} \approx 11)$ was found to be $165 \mathrm{~nm}$. After sonification for 10 minutes, the measured hydrodynamic diameter was $25 \mathrm{~nm}$, indicating that primary particles form weakly connected aggregates.

\subsection{Ceria nanoparticles}

The surface properties of synthesized ceria were determined. The effect of electrolyte concentration $\left(10^{-2} \mathrm{~mol} \mathrm{dm}^{-3}\right.$ and $\left.10^{-3} \mathrm{~mol} \mathrm{dm}^{-3}\right)$ on the mass titration curve, surface charge densities, and the point of zero charge of ceria nanodispersion was examined by potentiometric mass titration. For each ionic strength the mass titrations was performed from initial acidic $\left(\mathrm{pH}_{\mathrm{in}} \approx 3\right)$, neutral $\left(\mathrm{pH}_{\mathrm{in}} \approx 6.2\right)$ and basic $\mathrm{pH}\left(\mathrm{pH}_{\mathrm{in}} \approx 11\right)$ of aqueous solutions. The results were presented on Figure 4. By increasing the mass concentration of solid particles the $\mathrm{pH}$ of the suspension reached the constant value. Whereas the mass titration curves,starting from acidic and basic $\mathrm{pH}$ region, did not coincide at the same $\mathrm{pH}$ value, the mass concentration being still insufficiently high, mass titration curves starting from the neutral $\mathrm{pH}$ region reached the plateau at a lower mass concentration (i.e. $10 \mathrm{~g} \mathrm{dm}^{-3}$ ). The point of zero charge for the ionic strengths of $10^{-2} \mathrm{~mol} \mathrm{dm}{ }^{-3}$ was found to beat $\mathrm{pH}_{\mathrm{pzc}}=$ $7.8 \pm 0.5$ and for ionic strength $10^{-3} \mathrm{~mol} \mathrm{dm}^{-3}$ atpH $\mathrm{pzc}_{\mathrm{c}}=8.7 \pm 0.3$. 


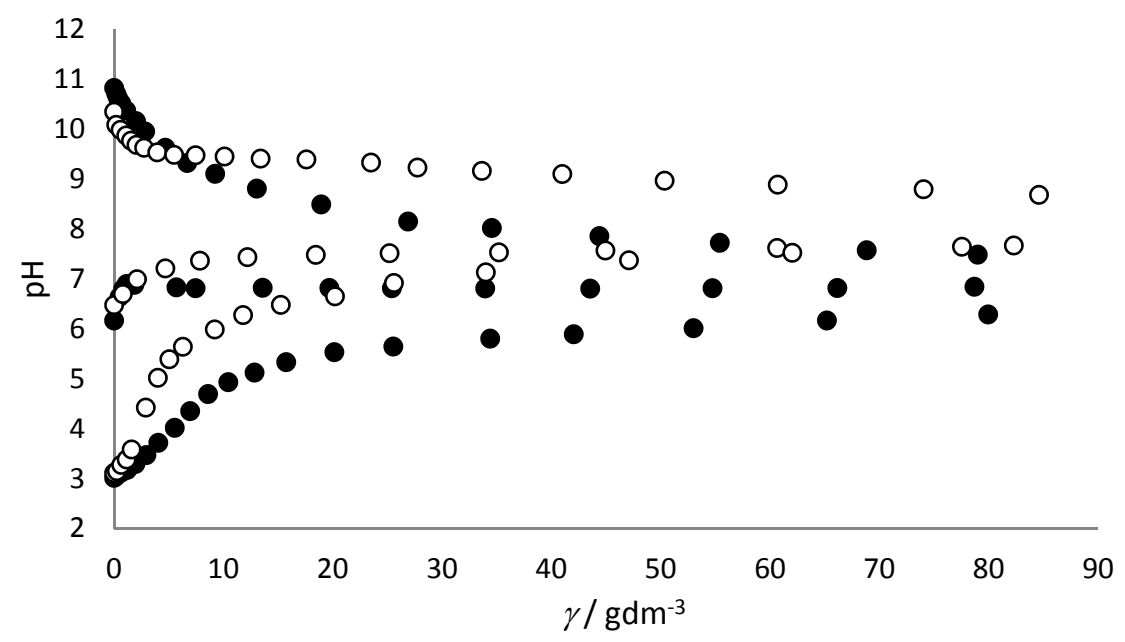

Figure 4Mass titrationsof ceria nanoparticles atdifferent ionic strength adjusted with $\mathrm{NaCl}:(\bullet) I_{c}=10^{-2}$ mol

$$
\mathrm{dm}^{-3} \text { and (०) } I_{\mathrm{c}}=10^{-3} \mathrm{~mol} \mathrm{dm}^{-3} \text { at } 25^{\circ} \mathrm{C}
$$

Table 1Points of zero charge $\left(\mathrm{pH}_{\mathrm{pzc}}\right)$ and isoelectric points $\left(\mathrm{pH}_{\mathrm{iep}}\right)$ for various cerium(IV) oxide samples

\begin{tabular}{|c|c|c|c|c|}
\hline $\mathrm{pH}_{\mathrm{pzc}}$ & $\mathrm{pH}_{\text {iep }}$ & Method & Electrolyte & Reference \\
\hline 8.1 & & $\begin{array}{c}\text { Potentiometric acid- } \\
\text { base titration }\end{array}$ & $0.005-0.3 \mathrm{~mol} \mathrm{dm}^{-3} \mathrm{KNO}_{3}$ & de Faria andTrasatti 1994 \\
\hline $8.6-10.0$ & $\begin{array}{c}\text { Potentiometric acid- } \\
\text { base titration }\end{array}$ & $0.1-0.5 \mathrm{~mol} \mathrm{dm}^{-3} \mathrm{NaClO}_{4}$ & Nabavi et al. 1993 \\
\hline 7.6 & Electrophoresis & $0.001-0.1 \mathrm{~mol} \mathrm{dm}^{-3} \mathrm{NaNO}_{3}$ & Ray et al. 1979 \\
\hline 7.1 & Mass titration & $0.1 \mathrm{~mol} \mathrm{dm}^{-3} \mathrm{NaNO}_{3}$ & Park and Regalbuto 1995 \\
\hline & 5.9 & Electrophoresis & $0.001 \mathrm{~mol} \mathrm{dm}^{-3} \mathrm{NaNO}_{3}$ & Hsu et al. 1988 \\
\hline & 8.5 & Microelectrophoresis & $\mathrm{n} / \mathrm{a}$ & Oh et al. 2010 \\
\hline & 6.2 & Electrophoresis & $\mathrm{HCl}+\mathrm{NaOH}^{-3}$ & Antonova et al. 2001 \\
\hline & 6.5 & Electrophoresis & Song et al. 2008 \\
\hline & 6 & Electrophoresis & $0.01 \mathrm{~mol} \mathrm{dm} \mathrm{NaNO}_{3}$ & $\begin{array}{c}\text { Suphantharida and Osseo- } \\
\text { Asare 2004 }\end{array}$ \\
\hline & 7.3 & Electrophoresis & $0.01 \mathrm{~mol} \mathrm{dm} \mathrm{NaCl}^{-3} \mathrm{NaCl}^{-3}$ & Hsu and Nacu 2004 \\
\hline
\end{tabular}

Surface charge densities as a function of $\mathrm{pH}$ were calculated from the slope of the mass titration curves by means of Eq. (1) and shown on Figure 5. As expected, surface charge densities increase with ionic strength. The broad point of zero charge regions, i. e. flat surface charge densities curves, was found for both examined ionic strengths, indicating low surface charge densities of ceria particles. Additionally the broad electroneutrality region could be the reason for a wide range of determined $\mathrm{pH}_{\mathrm{pzc}}$ values. These results are in accordance with 
literature, Table 1. The shift of point of zero charge, by increase of ionic strength, indicates the preferential association of chloride toward ceria surfaces.

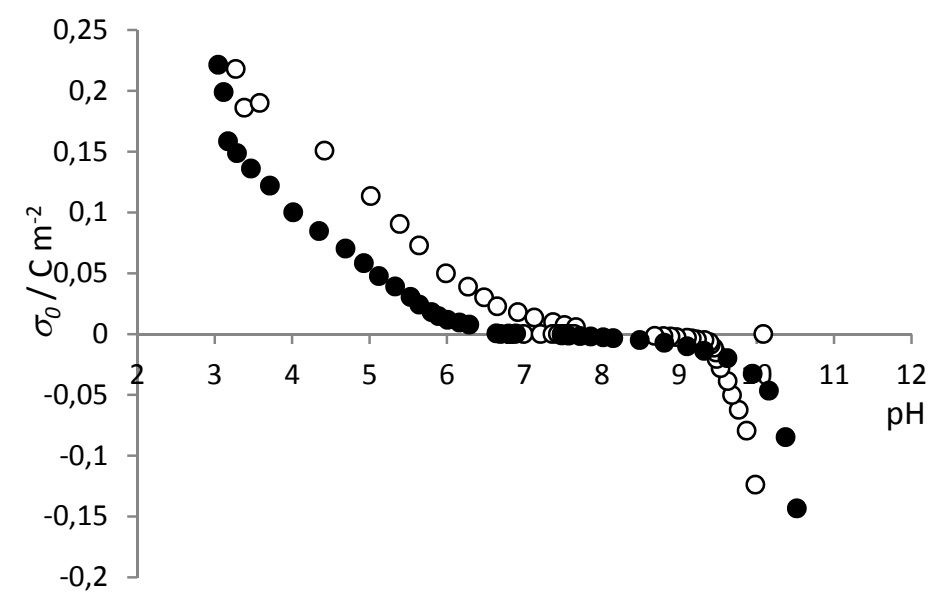

Figure5Surface charge densities of cerium(IV) oxide nanoparticles with the specific surface area $169 \mathrm{~m}^{2} / \mathrm{g}$ dispersed in the aqueous solution calculated using eq (1) for ionic strength $(\bullet) I_{c}=10^{-2} \mathrm{~mol} \mathrm{dm}^{-3}$ and (०) $I_{\mathrm{c}}=$ $10^{-3} \mathrm{~mol} \mathrm{dm}^{-3}$ at $25^{\circ} \mathrm{C}$.

The electrokinetic potentials of ceria nanoparticles at two concentrations of sodium chloride were measured, the results were presentedin Figure 6. The negligible influence of ionic strength on the isoelectric point was found. However the effect of electrolyte concentration is more apparent on positively charged ceria nanoparticles indicating slightly pronounced affinity of chloride ions toward ceria nanoparticles surface. Isoelectric points for both examined ionic strength $\left(I_{c}=10^{-2} \mathrm{~mol} \mathrm{dm}^{-3}\right.$ and $\left.I_{\mathrm{c}}=10^{-3} \mathrm{~mol} \mathrm{dm}^{-3}\right)$ were found to be at $\mathrm{pH}_{\mathrm{iep}}=6.5$, whichoverlapped with the region of the observed points of zero charge. 


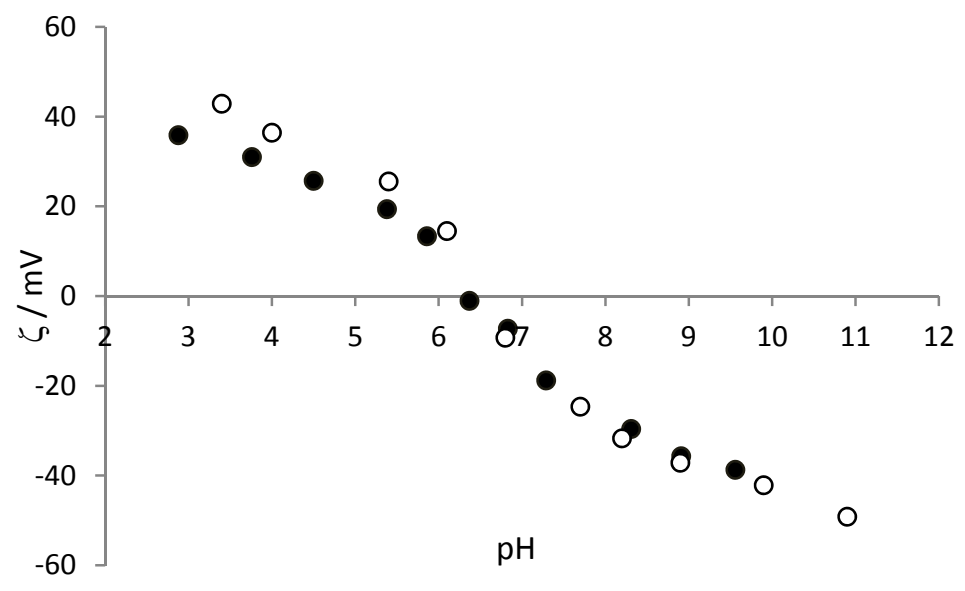

Figure 6. Electrokinetic $\zeta$-potential of cerium(IV) oxide nanoparticles dispersed in the aqueous $\mathrm{NaCl}$ solution measured for two ionic strength $I_{c}=10^{-2} \mathrm{~mol} \mathrm{dm}^{-3}(\bullet)$ and $I_{\mathrm{c}}=10^{-3} \mathrm{~mol} \mathrm{dm}^{-3}(\mathrm{O})$ at $25^{\circ} \mathrm{C}$.

As is verified by HR-TEM, the ceria nanocrystals are bounded mainly by the $\{111\}$ and $\{100\}$ planes. All present planes are exposed to the aqueous electrolyte solution contributing to the overall surface charge. Additionally, mutual effects of different crystal planes at the same nanoparticle, connected through the bulk of the crystal, could not be ignored. Assuming a simple 2-pK model (Yates et al. 1974,Rudziński et al. 1998),for the reactions at ceria nanoparticle surfaces, the thermodynamic parameters of surface protonation equilibrium reactions were estimated by fitting the experimentally obtained surface charge densities (Figure 5) and electro kinetic potential data (Figure 6). The difference in the thermodynamic equilibrium constants of the surface protonation of negative ceria surface sites and the surface protonation of neutral ceria surface sites was found to be $\Delta \mathrm{p} K=8.4$. According to the 2-pK model, the higher the difference in thermodynamic equilibrium constants the broader the electro neutrality region is.

$$
\begin{array}{lll}
\equiv \mathrm{CeO}^{-}+\mathrm{H}^{+} \square & \equiv \mathrm{CeOH} \quad \mathrm{p} K_{1}=-3.0 \\
\equiv \mathrm{CeOH}+\mathrm{H}^{+} \square & \equiv \mathrm{CeOH}_{2}^{+} \quad \mathrm{p} K_{2}=-11.4
\end{array}
$$

It should be noticed that 2-pK model is a rough approximation which assumes one kind of amphotheric surface sites at the ceria surface. This approximation is meaningful in the sense of applied experiments in which average surface properties are measured. 


\subsection{Macroscopic ceria crystal planes}

Inner surface potentials of ceria $\{100\}$ and ceria $\{111\}$ crystallographic planes were obtained by means of a single crystal electrode. The response and reproducibility of ceria electrodes were tested prior to measurements. It was found that the measured signal was stable and that the electrode potential didn't change during a long period. The reversibility of the electrode potential was also tested and hysteresis was not found. The acid base potentiometric titration with glass electrode and two ceria single crystal electrode $\{111\}$ and $\{100\}$ were performed. During titrations, the electrode potential $\left(E_{\mathrm{SCr}}\right)$ of Single Crystal Electrodes were measured. From the inflection point of the $E_{\mathrm{SCr}}(\mathrm{pH})$ function the point of zero potential $\left(\mathrm{pH}_{\mathrm{pzp}}\right)$ was determined. Knowing the value of $\mathrm{pH}_{\mathrm{pzp}}$ electrode potentials were converted to inner surface potentials $\Psi_{0}$ (Preočanin and Kallay 2013). Results for the $\{100\}$ and $\{111\}$ ceria crystal planes at two concentration of potassium chloride were shown on Figures 7 and 8 . Measured $\Psi_{0}(\mathrm{pH})$ functions differ for two examined ceria planes. However the inner surface potentials of both planes depend on the ionic strength having a broad electroneutrality region, between $\mathrm{pH}=6$ and $\mathrm{pH}=9$ (for lower ionic strength $I_{c}=10^{-3} \mathrm{~mol}$ $\mathrm{dm}^{-3}$ ) and even broader between $\mathrm{pH}=4$ and $\mathrm{pH}=9$ (for higher ionic strength $I_{c}=10^{-2} \mathrm{~mol}$ $\mathrm{dm}^{-3}$ ) making determination of point of zero potential inaccurate. The points of zero potential evaluated from the inflection point are: $\mathrm{pH}_{\mathrm{pzp}}(111)=7.4 \pm 0.6$, and $\mathrm{pH}_{\mathrm{pzp}}(100)=7.3 \pm 0.2$. It was assumed that point of zero potential do not depend on ionic strength being near the electroneutrality condition ( $\Psi_{0}=\sigma_{0}=\zeta=0$ ). At sufficiently low electrolyte concentrations, the isoelectric point and the point of zero charge are equal and coincide with the pristine point of zero charge (electroneutrality point) and also with the point of zero potential, making evaluation of the surface potentials from the measured single crystal electrode potentials simple. Whereas at higher electrolyte concentrations the situation in no more simple and $\mathrm{pH}_{\text {iep }}, \mathrm{pH}_{\mathrm{pzc}}$ and $\mathrm{pH}_{\mathrm{pzp}}$ are shifted from $\mathrm{pH}_{\mathrm{eln}}$. From the shifts of $\mathrm{pH}_{\text {iep }}$ and $\mathrm{pH}_{\mathrm{pzc}}$ values it might be concluded that the surface association affinities of anions and cations are not same (Kallay et al. 2007).

The difference of measured $\Psi_{0}(\mathrm{pH})$ curves of two examined ceria surfaces is more evident in the acidic region. The slopes of both $\Psi_{0}(\mathrm{pH})$ functions in the acidic region (between $\mathrm{pH}=3$ and $\mathrm{pH}=4$ ) are lover then Nernstian, being (for $I_{c}=10^{-3} \mathrm{~mol} \mathrm{dm}^{-3}$ ) $-33.1 \mathrm{mV}$ and $-22.2 \mathrm{mV}$, for the $\{111\}$ and the $\{100\}$ ceria crystal planes respectively. 


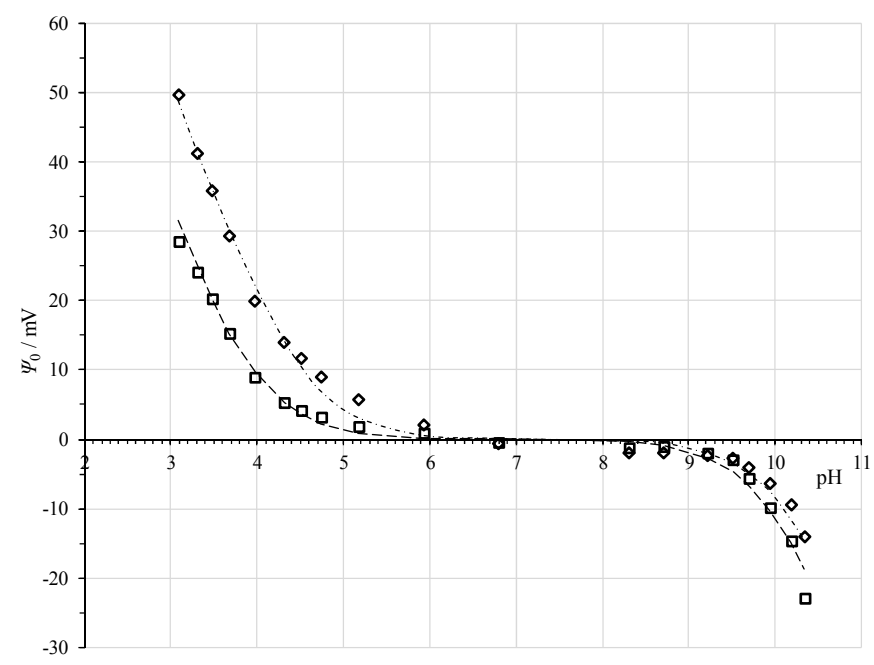

Figure 7The inner surface potential ofthe $\{100\}, \square$, and the $\{111\}, \diamond$, cerium(IV) oxide surface planes in the aqueous $\mathrm{KCl}$ solution for ionic strength $I_{c}=10^{-3} \mathrm{~mol} \mathrm{dm}^{-3}$ at $25^{\circ} \mathrm{C}$. Lines present the best fit for the MUSIC model. $\{100\}: \Gamma_{\text {tot }}\left(\equiv \mathrm{Ce}_{2} \mathrm{O}\right)=2.28 \times 10^{-5} \mathrm{~mol} \mathrm{~m}^{-2} ;\{111\}: \Gamma_{\text {tot }}\left(\equiv \mathrm{Ce}_{1} \mathrm{O}\right)=\Gamma_{\text {tot }}\left(\equiv \mathrm{Ce}_{3} \mathrm{O}\right)=1.31 \times 10^{-5} \mathrm{~mol} \mathrm{~m}^{-2}$; thermodynamic equilibrium constants are listed in Table 2.

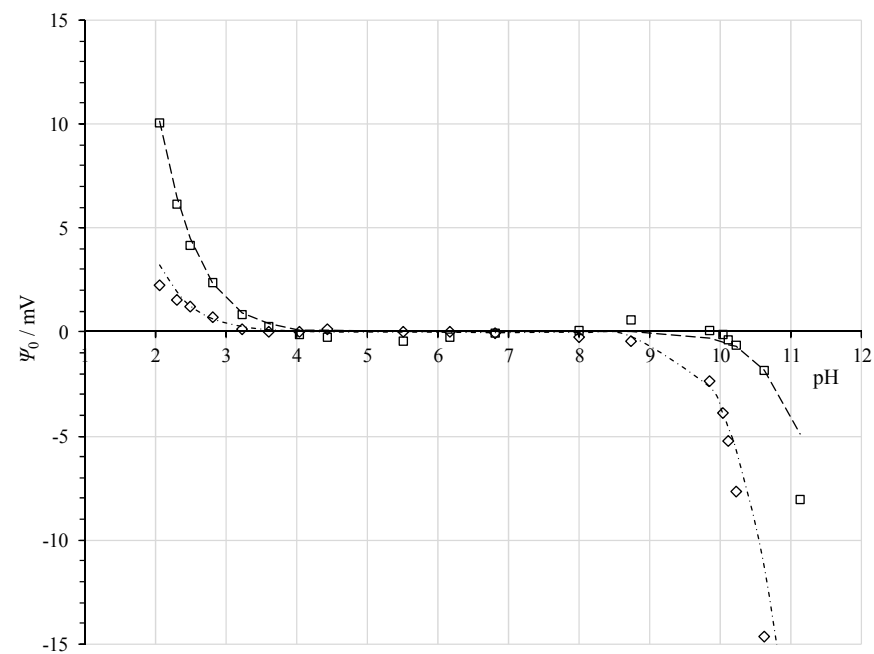

Figure 8The inner surface potential of (100), $\square$, and (111), $\diamond$, cerium(IV) oxide surface planes in aqueous the $\mathrm{KCl}$ solution for ionic strength $I_{c}=10^{-2} \mathrm{~mol} \mathrm{dm}^{-3}$ at $25{ }^{\circ} \mathrm{C}$. Lines present the best fit for the MUSIC model. $\{100\}: \Gamma_{\text {tot }}\left(\equiv \mathrm{Ce}_{2} \mathrm{O}\right)=2.28 \times 10^{-5} \mathrm{~mol} \mathrm{~m}^{-2} ;\{111\}: \Gamma_{\text {tot }}\left(\equiv \mathrm{Ce}_{1} \mathrm{O}\right)=\Gamma_{\text {tot }}\left(\equiv \mathrm{Ce}_{3} \mathrm{O}\right)=1.31 \times 10^{-5} \mathrm{~mol} \mathrm{~m}^{-2}$; thermodynamic equilibrium constants are listed in Table 2.

The $\mathrm{CeO}_{2}$ crystal structure is cubic (fluorite) with the crystal cell parameter $a=$ $5.4110 \AA$ (Wyckoff 1963). The atomic structure of $\mathrm{CeO}_{2}$ surfaces, especially regarding the positions and coordination of oxygen atoms has only recently been successfully imaged using 
chromatic (Cc) and spherical (Cs) aberrations corrected high-resolution electron microscopy (Lin et al. 2014). This study resolved the structure of active sites for catalysis which is of essential importance in research and application of ceria nanoparticles. Apart from nanoparticles, the same findings can be scaled to macroscopic levels, i.e. single crystals. It has been found (Lin et al. 2014) that the $\{111\}$ surface has an $O$ termination and the $\{100\}$ surface has a mixture of $\mathrm{Ce}, \mathrm{O}$, and reduced $\mathrm{CeO}$ terminations.

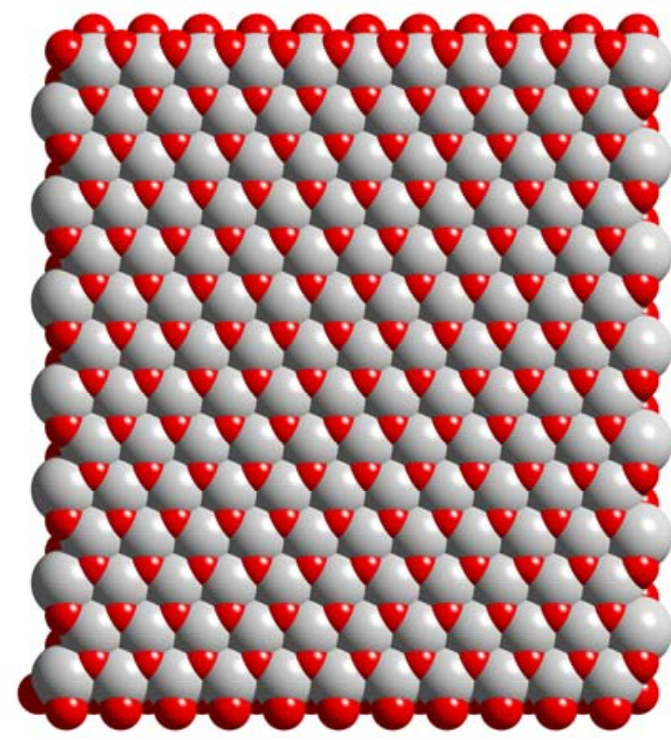

(a)

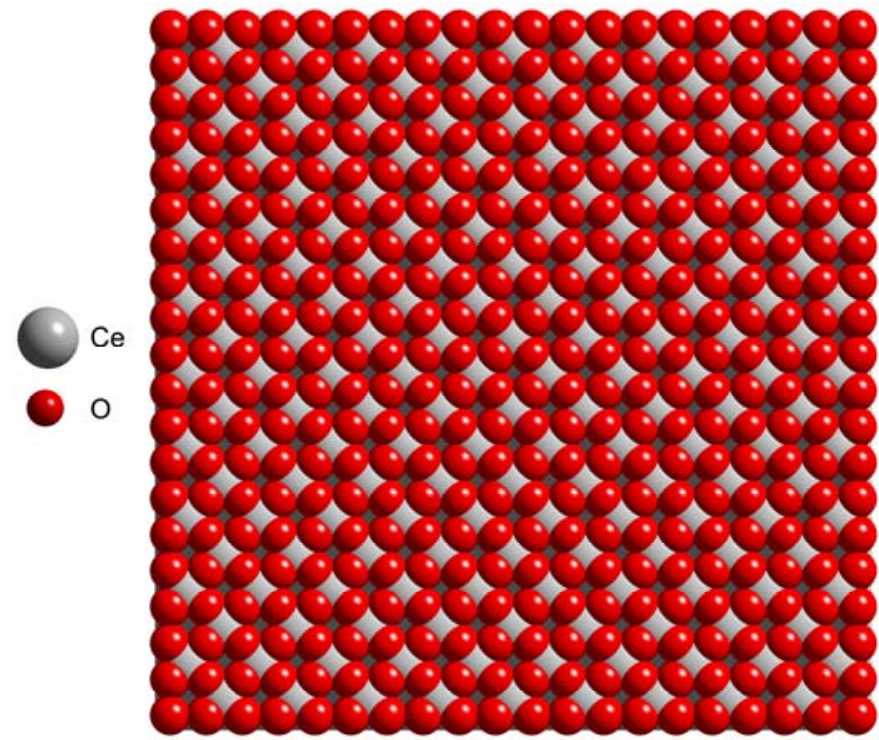

(b)

Figure 9 The stoichiometric composition of the $\{111\}$, (a) and the $\{100\}$, (b) ceria surfacedrawn byDiamond software for visualization of crystal structures (Diamond).

The thermodynamic of surface equilibrium reactionsof the $\mathrm{CeO}_{2}$ specific surface sites was investigated by means of the Multi Site Complexation Model (van Riemsdijk and 1986, Hiemstra et al. 1989, Hiemstra and van Riemsdijk 1996). The MUSIC model relies greatly on crystallographic parameters and information calculated from them. The surface oxygen atoms position and coordination are important in estimating the active hydroxyl surface sites concentration $\left(\Gamma_{\text {tot }}\right)$. The surface concentration of hydroxyl groups and surface cerium atoms is calculated from cell dimensions and by an observation of crystal surfaces composition. The coordination of different terminal active sites atoms was explored using Diamond software for visualization of crystal structures (Diamond). All previous investigations of ceria surfaces (Namaiet al.2003,Zhanget al. 2011) showed that various high energy surface defect structures 
are very common. It is therefore reasonable to expect certain discrepancy between model calculations and experimental values.

\subsubsection{Ceria $\{111\}$ crystal plane}

The stoichiometric composition of the $\{111\}$ surface, with one kind of O-terminal active site (triple-coordinated oxygen atoms, $\equiv \mathrm{Ce}_{3}-\mathrm{O}$ ) and one kind of Ce-terminal active site (三Ce),was shown on Figure 9a. Surface oxygen and cerium atoms react with water moleculeforming triple coordinated hydroxyl sites $\left(\equiv \mathrm{Ce}_{3}-\mathrm{OH}\right)$ and single-coordinated hydroxyl sites $\left(\equiv \mathrm{Ce}_{1}-\mathrm{OH}\right)$ :

\section{Reakcija}

Since there are multiple sites present on that surface, the MUSIC model was chosen for the calculation of thermodynamic parameters of surface reactions. The two-step protonation mechanism of amphoteric $\mathrm{Ce}_{1}$-terminal active sites assumes the following surface reactions and corresponding thermodynamic equilibrium constants:

$$
\begin{aligned}
& \equiv \mathrm{Ce}_{1} \mathrm{O}^{-1 / 2}+\mathrm{H}^{+}(\mathrm{aq}) f \equiv \mathrm{Ce}_{1} \mathrm{OH}^{+1 / 2} \quad K_{1,1}^{\mathrm{o}}=\exp \left(\Psi_{0} F / R T\right) \cdot \frac{\left\{\equiv \mathrm{Ce}_{1} \mathrm{OH}^{+1 / 2}\right\}}{\left\{\equiv \mathrm{Ce}_{1} \mathrm{O}^{-1 / 2}\right\} \cdot a_{\mathrm{H}^{+}}} \\
& \equiv \mathrm{Ce}_{1} \mathrm{OH}^{+1 / 2}+\mathrm{H}^{+}(\mathrm{aq}) f \equiv \mathrm{Ce}_{1} \mathrm{OH}_{2}^{3 / 2} \quad K_{1,2}^{\mathrm{o}}=\exp \left(\Psi_{0} F / R T\right) \cdot \frac{\left\{\equiv \mathrm{Ce}_{1} \mathrm{OH}_{2}^{3 / 2}\right\}}{\left\{\equiv \mathrm{Ce}_{1} \mathrm{OH}^{1 / 2}\right\} \cdot a_{\mathrm{H}^{+}}}
\end{aligned}
$$

where a curly brace denotes surface concentration (the amount or number of moles per surface area) and $\Psi_{0}$ is the inner surface potential affecting the state of ionic species being directly bound to the surface, and $a_{\mathrm{H}^{+}}$is arelative activity of the $\mathrm{H}^{+}$ions in the bulk of the solution. Other symbols have their usual meanings.

The two-step protonation mechanism of amphoteric O-terminal active sites (triplecoordinated oxygen atoms, $\equiv \mathrm{Ce}_{3}-\mathrm{O}$ ) assumes the following surface reactions and thermodynamic equilibrium constants:

$$
\begin{aligned}
& \equiv \mathrm{Ce}_{3} \mathrm{O}^{-1 / 2}+\mathrm{H}^{+}(\mathrm{aq}) f \equiv \mathrm{Ce}_{3} \mathrm{OH}^{+1 / 2} \quad K_{3,1}^{\mathrm{o}}=\exp \left(\Psi_{0} F / R T\right) \cdot \frac{\left\{\equiv \mathrm{Ce}_{3} \mathrm{OH}^{+1 / 2}\right\}}{\left\{\equiv \mathrm{Ce}_{3} \mathrm{O}^{-1 / 2}\right\} \cdot a_{\mathrm{H}^{+}}} \\
& \equiv \mathrm{Ce}_{3} \mathrm{OH}^{+1 / 2}+\mathrm{H}^{+} \text {(aq) } f \equiv \mathrm{Ce}_{3} \mathrm{OH}_{2}^{3 / 2} \quad K_{3,2}^{\mathrm{o}}=\exp \left(\Psi_{0} F / R T\right) \cdot \frac{\left\{\equiv \mathrm{Ce}_{3} \mathrm{OH}_{2}^{3 / 2}\right\}}{\left\{\equiv \mathrm{Ce}_{3} \mathrm{OH}^{1 / 2}\right\} \cdot a_{\mathrm{H}^{+}}}
\end{aligned}
$$


From crystal geometrythe total surface concentration, $\Gamma_{\text {tot }}$, for each site was calculated and used in modeling $\left(\Gamma_{\text {tot }}\left(\equiv \mathrm{Ce}_{1}-\mathrm{O}\right)=\Gamma_{\text {tot }}\left(\equiv \mathrm{Ce}_{3}-\mathrm{O}\right)=1.31 \times 10^{-5} \mathrm{~mol} \mathrm{~m}{ }^{-2} ; 7.9\right.$ sites $\left./ \mathrm{nm}^{2}\right)$. At Figures 7 and 8 the evaluated $\Psi_{0}(\mathrm{pH})$ curves for the $\{111\}$ ceria crystal plane were overlapped over experimental data, and the values of the obtained thermodynamic equilibrium constant were listed in Table 2.

The thermodynamic equilibrium constants of the first protonation, i.e. the protonation of negative surface sites, are higher than values of the second protonation, i.e. the protonation of the surface sites with charge $z=+1 / 2$, for both triple and single coordinated hydroxide surface sites, indicating that surface species with charge $z=+3 / 2$ are not present. The values of the thermodynamic equilibrium constants of reactions 6 and 8 aresignificantly lower than 1 $\left(\mathrm{p} K_{n, 2} \rightarrow 0\right)$, moreover they exhibit negligible impact on the calculated inner surface potential curve. This finding is inaccordance with the prediction of Hiemstra et al. 1989, which had stressedthat nature generally allowed only those surface species to be present in aqueous solutions which had a charge (absolute value) equal to or lower than one.

Table 2Thermodynamic parameters of the surface sites at ceria $\{111\}$ and $\{100\}$ planes, obtained by means of the MUSIC model by fitting the measured innersurface potential data presented on Figures 7 and 8

\begin{tabular}{|c|c|c|c|c|c|c|c|c|}
\hline surface & $\frac{I_{c}}{\mathrm{~mol} \mathrm{dm}^{-3}}$ & $n$ & & Eq. & $\frac{10^{5} \Gamma_{\text {tot }}}{\mathrm{mol} \mathrm{m}^{-2}}$ & $\mathrm{p} K_{n, 1}$ & $\mathrm{p} K_{n, 2}$ & $\mathrm{pH}_{\mathrm{pzc}}$ \\
\hline \multirow{2}{*}{111} & \multirow{3}{*}{$10^{-3}$} & 3 & $\equiv \mathrm{Ce}_{3}-\mathrm{OH}$ & 7,8 & 1.31 & -12.9 & 0 & \multirow{2}{*}{7.3} \\
\hline & & 1 & $\equiv \mathrm{Ce}_{1}-\mathrm{OH}$ & 5,6 & 1.31 & -1.7 & 0 & \\
\hline$\{100\}$ & & 2 & $\equiv \mathrm{Ce}_{2}-\mathrm{OH}$ & 9,10 & 2.27 & -13.4 & -0.4 & 6.9 \\
\hline \multirow{2}{*}{111} & \multirow{3}{*}{$10^{-2}$} & 3 & $\equiv \mathrm{Ce}_{3}-\mathrm{OH}$ & 7,8 & 1.31 & -12.7 & 0 & \multirow{2}{*}{6.0} \\
\hline & & 1 & $\equiv \mathrm{Ce}_{1}-\mathrm{OH}$ & 5,6 & 1.31 & 0.7 & 0 & \\
\hline$\{100\}$ & & 2 & $\equiv \mathrm{Ce}_{2}-\mathrm{OH}$ & 9,10 & 2.27 & -14.7 & 1.1 & 6.8 \\
\hline
\end{tabular}

* $n$ is a coordination number of surface oxygen atoms 


\subsubsection{Ceria $\{100\}$ crystal plane}

Figure $9 \mathrm{~b}$ shows the stoichiometric composition of the $\{100\}$ surface. At the $\{100\}$ planethe only one kind of site is visible (double-coordinated oxygen atoms, $\equiv \mathrm{Ce}_{2}-\mathrm{O}$ ). $\mathrm{Ce}$ atoms are too far from the surface to be considered active. It can also be noted that oxygen atoms are much closer to each other, and more exposed (also closer to the surface in comparison to $\{111\}$ oxygen atoms). The calculatedtotal double-coordinated surface sites concentration $\left(\Gamma_{\text {tot }}\left(\equiv \mathrm{Ce}_{2}-\mathrm{O}\right)=2,27 \times 10^{-5} \mathrm{~mol} \mathrm{~m}{ }^{-2} ; 13.7\right.$ sites $\left./ \mathrm{nm}^{2}\right)$ is higher in comparison with individual surface sites concentrations of singly- and triply-coordinated surface sites present at the $\{111\}$ plane. This value was used in the calculations. Regarding the difference in sites' densities, it has to be mentioned that the $\{111\}$ ceria surface has two active sites which summarized give slightly higher values of $\Gamma_{\text {tot. }}$.

The two-step protonation mechanism of amphoteric double-coordinated oxygen atoms $\left(\equiv \mathrm{Ce}_{2} \mathrm{O}\right)$ assumes the following surface reactions and thermodynamic equilibrium constants:

$$
\begin{aligned}
& \equiv \mathrm{Ce}_{2} \mathrm{O}^{-1}+\mathrm{H}^{+}(\mathrm{aq}) f \equiv \mathrm{Ce}_{2} \mathrm{OH}^{0} \quad K_{2,1}^{\mathrm{o}}=\exp \left(\Psi_{0} F / R T\right) \cdot \frac{\left\{\equiv \mathrm{Ce}_{2} \mathrm{OH}^{0}\right\}}{\left\{\equiv \mathrm{Ce}_{2} \mathrm{O}^{-1}\right\} \cdot a_{\mathrm{H}^{+}}} \\
& \equiv \mathrm{Ce}_{2} \mathrm{OH}^{0}+\mathrm{H}^{+}(\mathrm{aq}) f \equiv \mathrm{Ce}_{2} \mathrm{OH}_{2}^{+1} \quad K_{2,2}^{\mathrm{o}}=\exp \left(\Psi_{0} F / R T\right) \cdot \frac{\left\{\equiv \mathrm{Ce}_{2} \mathrm{OH}_{2}^{+1}\right\}}{\left\{\equiv \mathrm{Ce}_{2} \mathrm{OH}^{0}\right\} \cdot a_{\mathrm{H}^{+}}}
\end{aligned}
$$

At Figures 7 and 8, the calculated curves for the $\{100\}$ ceria crystal plane were overlapped over experimental data, and the values of the evaluated thermodynamic equilibrium constant were listed in Table 2.

The ceria crystal plane $\{100\}$ contains only one type of active surface sites $\left(\equiv \mathrm{Ce}_{2}-\mathrm{O}\right)$, again with the first protonation much pronounced compared with second protonation indicating an absence of surface sites with a charge equal to $z=+3 / 2$. Surface complexation modelling for plane with only one type of active surface site is a special case of MUSIC model identical to the 1-pK model (Hiemstra et al. 1989).

The value of the thermodynamic equilibrium constant of the protonation of negatively charged double coordinated surface sites at the $\{100\}$ ceria crystal plane $\mathrm{p} K_{2,1}$ are higher compared to the values of equilibrium constants obtained for single $\left(\mathrm{p} K_{1,1}\right)$ and triple $\left(\mathrm{p} K_{3,1}\right)$ coordinated surface sites at the $\{111\}$ plane. The higher value of the thermodynamic 
equilibrium constant of the $\{100\}$ plane results inthe lower slope of the $\Psi_{0}(\mathrm{pH})$ function in the acidic region. However, for the doubly-coordinated surface sites the difference in $\Delta \mathrm{p} K_{2}=$ $\mathrm{p} K_{2,1}-\mathrm{p} K_{2,2}=-13.0\left(\right.$ for $I_{c}=10^{-3} \mathrm{~mol} \mathrm{dm}^{-3}$ ) and $\Delta \mathrm{p} K_{2}=\mathrm{p} K_{2,1}-\mathrm{p} K_{2,2}=-15.8$ (for $I_{c}=10^{-2}$ mol $\mathrm{dm}^{-3}$ ) are found to be higher than difference of thermodynamic equilibrium constants obtained for surface sites present at the $\{111\}$ ceria crystal plane, resulting in a wider electroneutrality region of the ceria/aqueous electrolyte interface.

Using the evaluated thermodynamic equilibrium constants surface charge densities and electrokinetic potentials for both ceria crystal planes were calculated. The calculated values of surface charge densities and electrokinetic potentials are significantly lower than measured values for ceria nanoparticles. The discrepancy of results may lay in the fact that model didn't assume the influence of interfacial water molecules and the association of the counterions within electrical interfacial layer (Lützenkirchen et al. 2015). However, as in the case of ceria nanoparticles, the broad electroneutrality region was observed also for the ceria flat surface. At low or zero surface potential the electrostatic repulsion is diminished and aggregation of ceria nanoparticles along uncharged crystal planes occurs which was confirmed by HR-TEM (Figure 3). Aggregation of ceria nanoparticles along $\{100\}$ and $\{111\}$ crystal planes leads to the decreasing of effective surface area, and may be the reason of discrepancy of the data collected by different experimental technique.

The further research will be focused on the mutual effect of the surface planes at the same nanoparticle, therefore it is necessary to know exact surface structure and the surface densities of the particular surface sites.

\section{Conclusions}

As it is confirmed by the high resolution transmission electron microscopy the ceria nanoparticle is a single crystal and that its surface is made mostly of simple crystallographic planes $\{111\}$ and $\{100\}$. The point of zero charge and the isoelectric point of the synthesized ceria nanoparticles were found to be between $\mathrm{pH}_{\mathrm{pzc}}=7.5$ and 9.0(increases with increasing electrolyte concentration) and $\mathrm{pH}_{\mathrm{iep}}=6.5$ (slightly decreases with increasing electrolyte concentration). The shift of the point of zero charge slightly to the basic region by increasing ionic strength indicates a preferential association of anions towards the ceria nanoparticles surface.The surface characterization of colloid and nanoparticles, exhibiting different crystal planes to the aqueous electrolyte solution, provides some kind of average surface properties 
i.e.surface charge densities and electrokinetic potentials. Moreover due to aggregation of ceria nanoparticles the effective surface area exposed to the aqueous electrolyte solution has been reduced.

The inner surface potentials of ceria $\{111\}$ and $\{100\}$ crystal planes were measured by means of single crystal electrodes at different $\mathrm{pH}$ and ionic strength. The measured $\Psi_{0}(\mathrm{pH})$ function differ for two examined ceria planes, however the inner surface potentials of both planes depend on ionic strength having a broad electroneutrality region between $\mathrm{pH}=6$ and $\mathrm{pH}=9$. From measured $\Psi_{0}(\mathrm{pH})$ data and applying the MUSIC model the thermodynamic equilibrium constants of double coordinated $\equiv \mathrm{Ce}_{2}-\mathrm{OH}$ (at the $\{100\}$ ceria crystal plane) and single $\equiv \mathrm{Ce}_{1}-\mathrm{OH}$ and triple $\equiv \mathrm{Ce}_{3}-\mathrm{OH}$ coordinated (at the $\{111\}$ ceria crystal plane) were evaluated. The shape of the calculated surface charge densities of flat ceria surface planes is the same as obtained for ceria nanoparticles. Analyzing well-defined monocrystal surfaces, which form the colloid and nanoparticle, as well as the mutual effects of different crystal surfaces, leads to a better understanding of surface reactions and mutual interactions of adjacent crystal planes on average surface properties. 


\section{REFERENCES}

Antonova, A. A., Zhilina, O. V., Kagramanov, G. G., Kienskaya, K. I., Nazarov, V. V., Petropavlovskii, I. A., Fanasyutkina, I. E.: Synthesis and Some Properties of Cerium Dioxide Hydrosols. Colloid Journal 63, 662-667 (2001)

Delgado, A.V., Gonzalez-Caballero, F., Hunter, R.J., Koopal, L.K., Lyklema, J.: Measurement and interpretation of electrokinetic phenomena. J. Colloid Interface Sci. 309, 194-224 (2007)

Diamond - Crystal and Molecular Structure Visualization, Crystal Impact, v.4.0.5, http://www.crystalimpact.com/diamond(Sep 12015 )

de Faria, L. A., Trasatti, S.: The point of zero charge of CeO2. J. Colloid Interface Sci. 167, 352-357 (1994)

Gulicovski, J. J., Bračko, I., Milonjić, S. K., Morphology and the isoelectric point of nanosized aqueous ceria sols. Mater. Chem. Phys. 148, 868-873 (2014)

Hiemstra, T., van Riemsdijk, W.H., Bolt, G.H.: Multisite proton adsorption modeling at the solid/solution interface and (hydr)oxides: a new approach, I. Model description and evaluation of intrinstic reaction constants. J. Colloid Interface Sci. 133, 91-104 (1989)

Hiemstra, T., van Riemsdijk, W. H.: A Surface Structural Approach to Ion Adsorption: The Charge Distribution (CD) Model. J. Colloid Interface Sci. 179, 488-508 (1996)

Hiemstra, T., van Riemsdijk,W.H.: On the relationship between charge distribution, surface hydration, and the structure of the interface of metal hydroxides. J. Colloid Interface Sci. 301, $1-18$ (2006)

Hsu, W. P., Ronnquist, L., Matijevic, E.: Preparation and properties of monodispersed colloidal particles of lanthanide compounds. 2. Cerium(IV). Langmuir 4, 31-37 (1988)

Hsu, J.-P., Nacu, A: An experimental study on the rheological properties of aqueous ceria dispersions. J. Colloid Interface Sci. 274, 277-284 (2004)

Hunter, R.J.: Zeta Potentials in Colloid Science. Academic Press, London (1981)

Kallay, N., Dojnović, Z., Čop, A.: Surface potential at the hematite-water interface, J. Colloid Interface Sci. 286, 610-614 (2005)

Kallay, N., Žalac, S., Kovačević, D.: Thermodynamics of the solid/liquid interface. Its application to adsorption and colloid stability. In: Lützenkirchen, J. (ed.) Surface Complexation Modelling. Interface Science and Technology Series. Elsevier, Amsterdam (2006) 
Kallay, N., Preočanin, T., Ivšić, T.: Determination of Surface Potential from the Electrode Potential of a Single-Crystal Electrode. J. Colloid Interface Sci. 309, 21-27 (2007)

Kallay, N., Preočanin, T., Sapunar, M., Namjesnik, D.: Common surface potential of different crystal planes in electrical contact, Surface Innovations 2, 142-150 (2014)

Karakoti, A. S., Monteiro-Riviere, N. A., Aggarwal, R., Davis, J. P., Narayan, R. J., Self, W. T., McGinnis, J., Seal, S.: Nanoceria as Antioxidant: Synthesis and Biomedical Applications. JOM(1989) 60, 33-37 (2008)

Langford, J., Wilson, A.: Scherrer after sixty years: A survey and some new results in the determination of crystallite size. J. Appl. Crystallogr. 11, 102-103 (1978)

Lin Y., Wu, Z., Wen, J., Poeppelmeier, K. R., Marks, L. D.; Imaging the atomic surface structures of CeO2 nanoparticles. Nano Lett., 14, 191-196 (2014)

Lützenkirchen, J. (ed.): Surface Complexation Modelling. Interface Science and Technology Series. Elsevier, Amsterdam (2006)

Lützenkirchen, J., Heberling, F., Šupljika, F., Preočanin, T., Kallay, N., Johann, F., Weisser, L., Eng, P. J.: Structure-charge relationship - the case of hematite (001). Faraday Discussion $180,55-79(2015)$

Lyklema, J.: Fundamentals of Interface and Colloid Science, Vol. II: Solid-Liquid Interface. Academic Press, London (1995)

Melchionna M, Fornasiero, P.: The role of ceria-based nanostructured materials in energy applications. Materials Today 17, 369-357 (2014)

Monshi, A., Foroughi, M.R., Monshi, M.R.: Modified Scherrer Equation to Estimate More Accurately Nano-Crystallite Size Using XRD. World J. Nano Sci. Eng. 2, 154-160 (2012)

Morris, V., Fleming, P. G., Holmes, J. D., Morris, M. A.: Comparison of the preparation of cerium oxide nanocrystallites by forward (base to acid) and reverse (acid to base) precipitation. Chem. Eng. Sci 91, 102-110 (2013)

Nabavi, M., Spalla, O., Cabanet, B.: Surface chemistry of Nanometric Ceria Particles in Agueous Dispersions. J. Colloid Interface Sci. 160, 459-471 (1993)

Namai, Y., Fukui, K., Iwasawa, Y.: Atom-Resolved Noncontact Atomic Force Microscopic Observations of $\mathrm{CeO}_{2}$ (111) Surfaces with Different Oxidation States: Surface Structure and Behavior of Surface Oxygen Atoms J. Phys. Chem. B107, 11666-11673 (2003)

Noh, J. S., Schwarz, J. A.: Estimation of the point of zero charge of simple oxides by mass titration. J. Colloid Interface Sci. 130, 157-164 (1989) 
Ocana, M.: Preparation and properties of uniform praseodymium-doped ceria colloidal particles. Colloid Polym. Sci. 280, 274-281 (2002)

Oh, M.-H., Lee, J.-S., Gupta, S., Chang, F.-C., Singh, R. K.: Preparation of monodispersed silica particles coated with ceria and control of coating thickness using sol-type precursor. Colloids Surf. A 355, 1-6 (2010)

Ould-Moussa, N., Safi, M., Guedeau-Boudeville, M.-A., Montero, D., Conjeaud, H., Berret, J.-F.: In vitro toxicity of nanoceria: effect of coating and stability in biofluids. Nanotoxicology 8, 799-811 (2014)

Park, J., Regalbuto, J. R.: A simple, Accurate Determination of Oxide PZC and the Strong Buffering Effect of Oxide Surfaces at Incipient Wetness. J. Colloid Interface Sci. 175, 239252 (1995)

Preočanin, T., Kallay, N.: Application of «Mass titration» to Determination of Surface Charge of Metal Oxides. Croat. Chem. Acta 71, 1117-1125 (1998)

Preočanin, T., Kallay, N.: Point of Zero Charge and Surface Charge Density of TiO2 in Aqueous Electrolyte Solution as Obtained by Potentiometric Mass Titration. Croat. Chem. Acta 79, 95-106 (2006)

Preočanin, T., Kallay, N.: Effect of Electrolyte on the Surface Potential of Hematite in Aqueous Electrolyte Solutions, Surf. Eng. 24, 253-258 (2008)

Preočanin, T., Kallay, N.: Evaluation of surface potential from single crystal electrode potential. Adsorption 19, 259-267 (2013)

Ray, K. C., Sengupta, P. K., Roy, S. K.: Electrokinetic and adsorption studies on ceric oxideaqueous interface. Indian J. Chem., Sect. A: Inorg., Bio-inorg., Phys., Theor. Anal.

Chem.17A, 348-351 (1979)

Reed, K., Cormak, A., Kulkarni, A., Mayton, M., Sayle, D., Kleassig, F., Stadler, B.: Expolring the properties and applications of nanoceria: is there still pleanty of room at the bottom? Environ. Sci.: Nano 1, 390-405 (2014)

van Riemsdijk, W.H., Bolt, G.H., Koopal, L.K., Blaakmeer, J.: Electrolyte adsorption on heterogenous surfaces: adsorption models. J. Colloid Interface Sci. 109, 219-228 (1986)

Rudzinski, W., Charmas, R., Piasecki, W., Cases, J.M., Francois, M., Villieras, F., Michot, L. $\mathrm{J} .:$ Calorimetric studies of simple ion adsorption at oxide/electrolyte interface titration experiments and their theoretical analysis based on 2-pK charging mechanism and on the triple layer model. Colloid Surf. A 137, 57-68 (1998) 
Schindler, R., Stumm, W.: The surface chemistry of oxides, hydroxides, and oxide minerals. In: Stumm, W. (ed.) Aquatic Surface Chemistry, pp. 83-110. Wiley-Interscience, New York (1987)

Si, R., Flytzani-Stephanopoulos, M.: Shape and Crystal-Plane Effects of Nanoscale Ceria on the Activity of Au-CeO ${ }_{2}$ Catalysts for the Water-Gas Shift Reaction. Angew. Chem. Int. Ed. 47, 2884-2887 (2008)

Song, X. et al: Synthesis of $\mathrm{CeO}_{2}$-coated $\mathrm{SiO}_{2}$ nanoparticle and dispersion stability of its suspension. Mater. Chem. Phys. 110, 128-135 (2008)

Suphantharida, P., Osseo-Asare, K.: Cerium Oxide Slurries in CMP. Electrophoretic Mobility and Adsorption Investigations of Ceria/Silicate Interaction. Journal of The Electrochemical Society 151, G658-G662 (2004)

Wyckoff R. W. G., Crystal Structures, 1 (1963) p.239-444, Second edition. Interscience Publishers, New York, New York

$\mathrm{Xu}, \mathrm{J} ., \mathrm{Li}, \mathrm{G} ., \mathrm{Li}, \mathrm{L} ., \mathrm{CeO}_{2}$ nanocrystals: Seed-mediated synthesis and size control. Mater Res. Bul. 43, 990-995 (2008)

Yates, D.E., Levine, S., Healy, T.W: Site-binding model of the electrical double layer at the oxide/water interface. J. Chem. Soc. Faraday Trans. I 70, 1807-1818 (1974)

Zarzycki, P., Rosso, K. M., Chatman, S., Preočanin, T., Kallay, N., Piasecki, W.: Theory, experiment and computer simulation of the electrostatic potential at crystal/electrolyte interfaces, Croat. Chem. Acta 83, 457-474 (2010).

Zhang, C., Michaelidesa, A., Jenkins, S. J.: Theory of gold on ceria. Phys. Chem. Chem. Phys.13, 22-33 (2011)

Žalac S., Kallay, N.; Application of mass titration to the point of zero charge determination. J. Colloid Interface Sci. 149, 233-240(1992) 